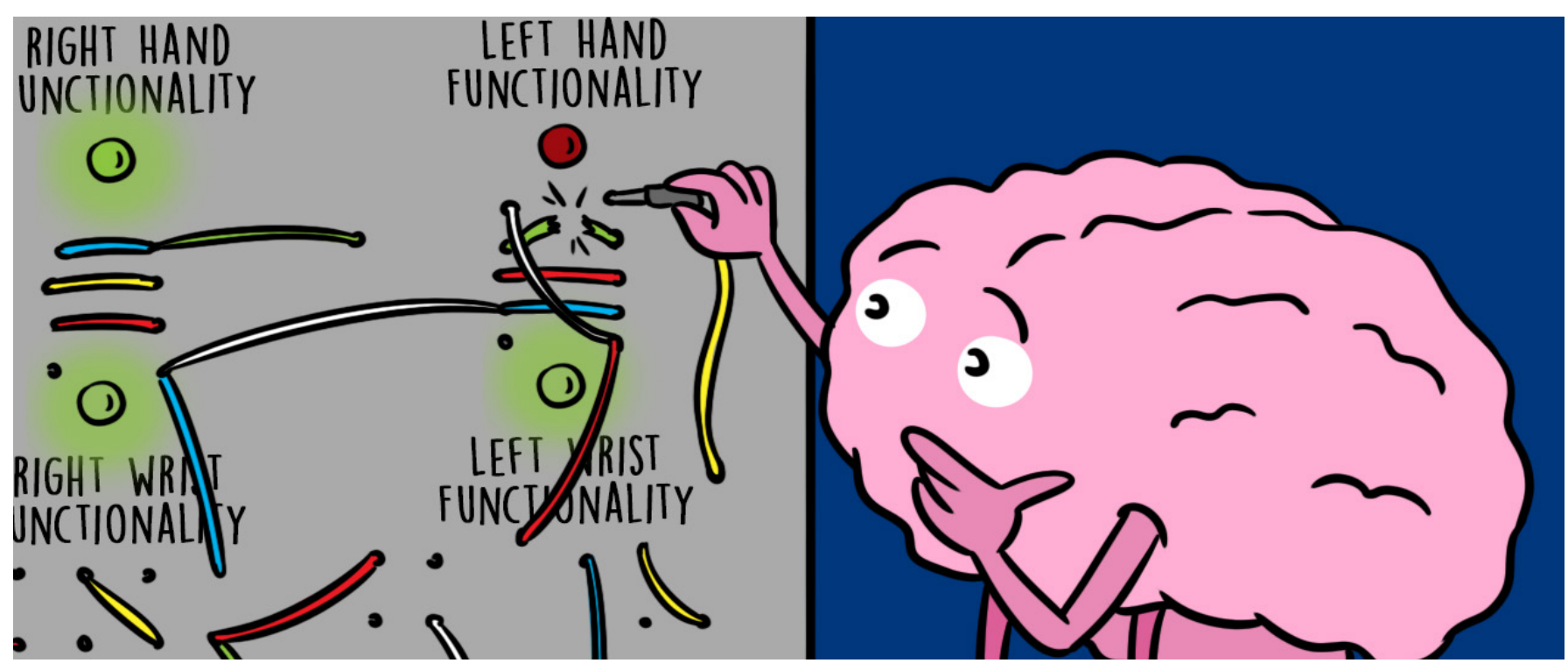

\title{
BIG SURPRISE: THE BRAIN CAN RECOVER MANY YEARS AFTER A STROKE
}

\section{J. David Spence*}

Robarts Research Institute, London, ON, Canada

REVIEWED BY:

CLARA

AGE: 11

\section{STROKE}

Sudden loss of function of part of the brain. This may be due to a hemorrhage (a bleed) into the brain, or due to blockage of a brain artery by a clot.
Most doctors think that after a patient has a stroke, recovery only happens for 6 months to a year; after that there is no point in continuing with rehabilitation therapy. We described a patient who had a severe stroke at age 15 and was left with a completely useless left hand. Then 23 years later, after he started swimming regularly to lose weight, he had some movement in the fingers of his left hand. He began intensive therapy with exercises using a special glove, and now, 37 years after the stroke, he is still improving. The way his brain "rewired" itself all over both sides of the brain is shown with a special imaging method called functional magnetic resonance imaging. This means that intensive physiotherapy and maybe new approaches to brain recovery including stem cell therapy, need to be tried much longer after the stroke than we used to think.

\section{INTRODUCTION}

What most doctors believe is that after a stroke, the patient can only recover for a short time, such as 6 months or a year. Young children who have strokes recover much better than people who have strokes as adults. 
STEM CELLS

Cells that are very primitive, that can develop into any kind of cell in the body.
This is a story of a man who had a stroke at age 15 and had no use of his left hand until he began to recover 23 years later, after taking up swimming to try to lose weight [1]. He is still improving 37 years after the stroke. His story gives hope for recovery much later than we thought possible, and suggests that intensive physiotherapy, and maybe new approaches to brain recovery such as stem cell therapy might improve recovery long after a stroke [2-5].

\section{THE STROKE}

In 1979, when he was 15 years old, a boy was going by train from his home in Windsor, Ontario, Canada, to join his parents who were visiting in Toronto, Ontario. He got off the train, carrying a heavy suitcase by his right hand. He walked the length of the train platform, down stairs, across the train station, then up stairs and across a wide plaza to where his parents were waiting to pick him up. He lifted the suitcase up into the trunk of the car, and got into the back seat. About 30 seconds later, as his father was making a left turn about a block from the train station, he fell over in the back seat, unconscious. He was taken to hospital in Toronto, and then a couple of days later was transferred to my hospital in London, Ontario because it was closer to his home.

It turned out that he was born with an extra rib in his neck called a cervical rib https://en.wikipedia.org/wiki/Cervical_rib. This is a rare abnormality; it happens in about 1 in 500 people, and strokes from this are very rare. The heavy suitcase had pulled his collar bone down onto the extra rib, pinching the artery to his right arm for long enough that the blood clotted. The clot backed its way down into the main artery that goes to both the brain and the arm on the right side. Then pieces of the clot went into the main artery to the front of the brain as well as into the artery that goes up through the bones in the neck to the back of the brain, and he had a severe stroke (Figure 1).

I was very worried, because besides the stroke, the artery to the right arm was blocked, and the blood supply to the right arm was very poor-I was concerned that we might have a 15-year-old boy with no use of either hand. So we treated him with drugs to prevent blood clotting in the hope that the blood flow to the right arm would return in time to save the hand, even though we were worried that this might cause him to have a bleed into the part of the brain that was softened by the severe stroke. It was a scary weekend, waiting to see what would happen.

Fortunately, the blood flow to the right arm recovered. However, he was left with a very severe stroke, with no movement at all in the left hand. He made some recovery over a few months, so he could walk and had some movement of his left shoulder, and he go back to school, but his right hand remained completely useless for 23 years. 


\section{FIGURE 1}

How the stroke happened. The heavy weight of the suitcase pulled the collar bone down, compressing the artery to the arm against an extra rib in the neck $\mathbf{A}$. This caused clotting that went back down into the brachiocephalic artery, also called the Innominate artery B. Clots broke off from both ends, going up the vertebral artery (black arrows, Panel C.) and the carotid artery, blocking the right middle cerebral artery (black arrows, Panel D.). Credits: A. Thoracic outlet: https:// en.wikipedia.org/wiki/ Thoracic_outlet_syndrome. B. Brachiocephalic artery: https://anatomyclass01. us/brachiocephalic-arterybranches/brachiocephalicartery-branches-anatomyof-subclavian-arteryhuman-anatomy-library/. C. Vertebral artery: https://en.wikipedia.org/ wiki/Vertebral_artery. D. Arteries at the base of the brain. By Dr. Johannes Sobotta - Atlas and Textbook of Human Anatomy Volume III Vascular System, Lymphatic system, Nervous system and Sense Organs, Public Domain, https:// commons. wikimedia.org/w/ index.php?curid=29121373.

\section{THE BEGINNING OF THE RECOVERY}

He was overweight, so in $2001 \mathrm{I}$ advised him to do some exercise to lose weight. He took up regular swimming, and a year later when he came back, he told me that he had noticed some movement in the fingers of his left hand, 23 years after the stroke. This was unheard of, so I called Dr. Dan Hanley at Johns Hopkins medical school in Baltimore to ask him what he thought was going on. He was very interested, because in his brain recovery center they had recently been using repeated movement of the large muscles of the shoulder and arm to try to improve recovery of hand function. He recommended that the patient try a physiotherapy device called a Saeboflex glove, that has small springs putting tension on the fingers: https://www.saebo.com/saeboflex/.

\section{PROGRESS IN STROKE RECOVERY}

With intensive physiotherapy using the Saeboflex glove, his left hand movement kept gradually improving, so that after a few years he was able to even
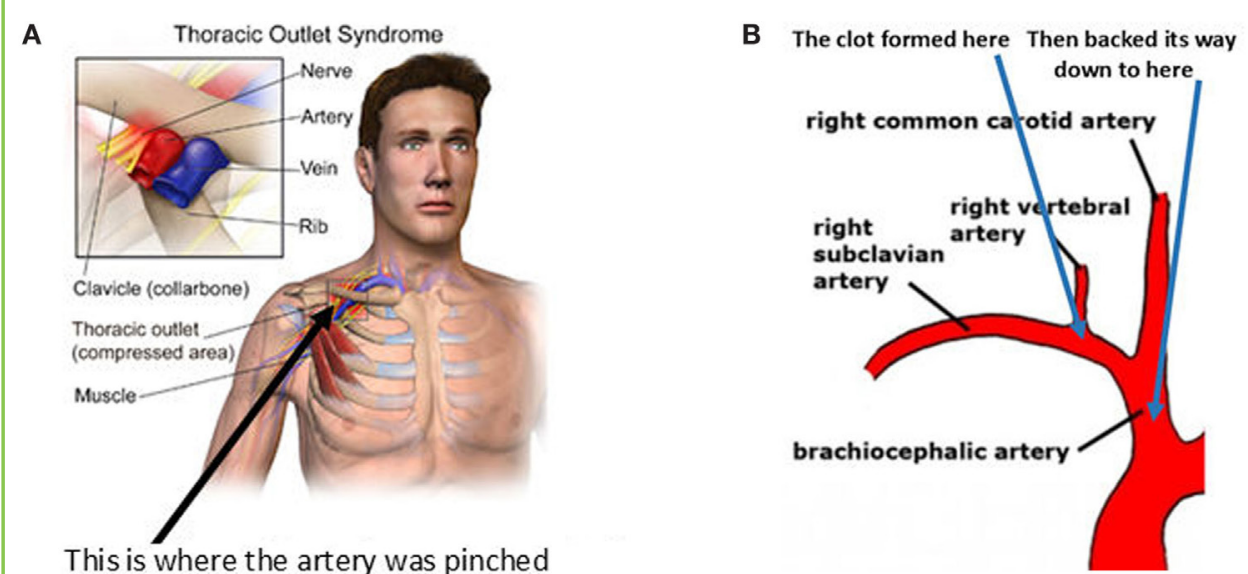

C Then chunks of clot broke off and went up the vertebral artery to the back of the brain, and the carotid artery to the front of the brain

D One chunk of clot blocked the main artery to the front of the brain, the middle cerebral artery (black arrow)

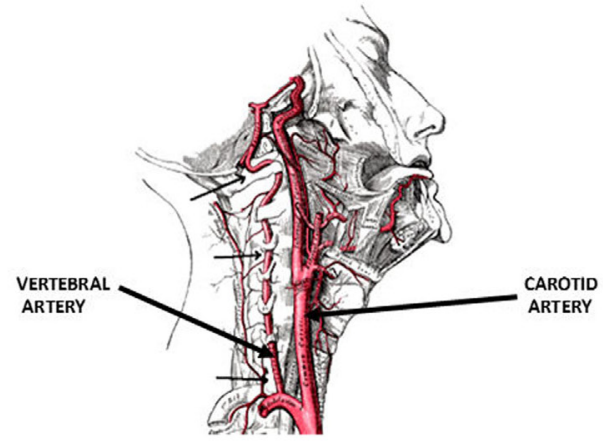


VERTEBRAL ARTERY

One on each side at the back of the neck; they run up through the bones of the neck to the back of the brain, and then join to form the basilar artery, at the base of the brain.

These are the arteries that are injured in chiropractic manipulation, or in car accidents, causing strokes at the back of the brain.

\section{CAROTID \\ ARTERIES}

Two large arteries in the front of the neck; they supply blood to the front of the brain. (Panel $\mathrm{C}$ of Figure 1).

\section{MAGNETIC}

RESONANCE

\section{IMAGING (MRI)}

A very strong electric magnet is switched on and off in the scanner; atoms in the body line up with the magnetic pole and then spin back, giving off radio waves that can be used to locate them to make a picture.

\section{FIGURE 2}

Functional MRI images showing the brain recovery on both sides of the brain. The figure is explained in box 1 .

[Reproduced by permission of the American Physiological Society from: Ref [1] pick up coins. He had slow but steady improvement of his hand function, that is still improving in 2018, more than 37 years after the stroke.

\section{HOW COULD THIS HAPPEN?}

What happens is that the brain sort of rewires itself. Nerve cells sprout extensions that spread out and connect with nerve cells in other parts of the brain. This allows other parts of the brain to take over the jobs that used to be done by the part of the brain that was damaged.

You can see this in Figure 2, showing results of a study called a functional magnetic resonance imaging (MRI) scan. MRI scans use a very powerful magnet that switches on and off. When the magnet switches on, it makes atoms in the cells spin to line up with the magnetic poles of the magnet. When the magnet switches off the atoms spin back, and they give off radio signals that can be detected and mapped, so that images of the brain can be made: https://en.wikipedia.org/wiki/Magnetic_resonance_imaging. Functional MRI assesses changes in blood flow in different parts of the brain during brain activity. The figure is explained in Box 1.

By detecting increases in blood flow in a part of the brain during activity, it is possible to map where in the brain the "rewiring" has happened. For example, the part of the brain where vision happens lights up when patients are shown something like a flashing checkerboard. One famous example is blind people who can "see" by making clicking noises and listening to the echos. This is called echolocation, and is like how bats see in the dark. It turns out that in people who are good at this, the part of the brain where vision normally occurs lights up when they are listening to sounds: http://www.cbc.ca/radio/quirks/sept-23-2017-1.4302012/ watch-this-blind-man-see-the-world-with-sound-1.4302029.

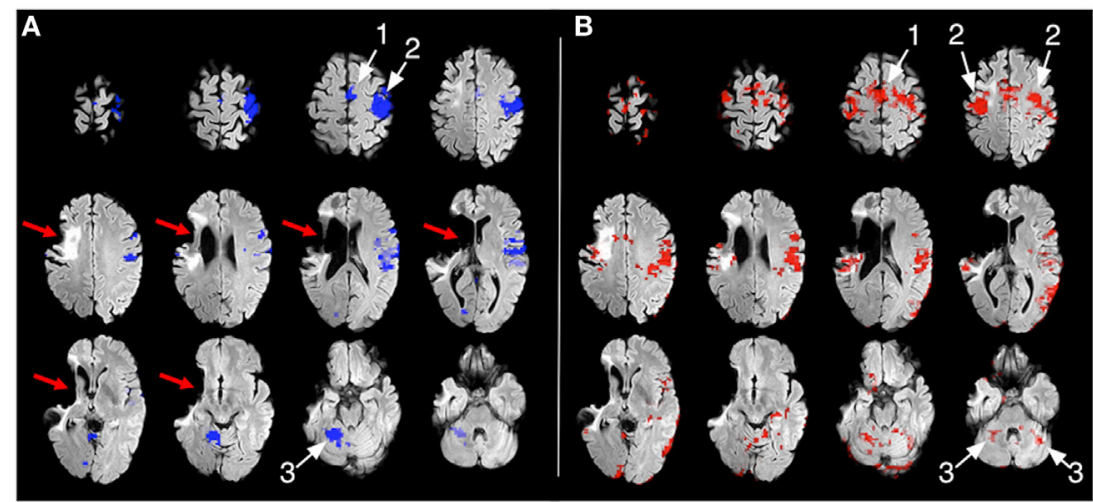

FIGURE 2 


\section{BOX 1}

Explanation for Figure 2.

\section{CEREBELLUM}

The part of the brain that coordinates movements; like muscle memory. (Shown by arrows marked 3 in panel B of Figure 2).

\section{MOTOR CORTEX}

The part of the brain that initiates movement; shown by white arrow 2 in panel A of Figure 2.

\section{SUPPLEMENTARY} MOTOR CORTEX

A small area in the brain that also is involved in movement; often automatic movements. (Panel A of Figure 2).
This shows slices of the brain in a magnetic brain scan, going from the top of the brain (in the top left of each picture), to the bottom of the brain (bottom right of each picture). The scan shows what parts of the brain "light up" with increased blood flow during movements of the normal right hand (Figure 2A) and movements of the left hand that was paralyzed by the stroke (Figure 2B). The images are shown the way imaging specialists call radiologists look at them (the left side of the image shows the right hemisphere), as if looking up at the brain from underneath. The two sides of the upper part of the brain are called the hemispheres. At the back of the brain near the bottom of the skull, the cerebellum controls coordination of movements. Normally the right hemisphere of the brain controls movement on the left side of the body, and the left side of the cerebellum controls coordination on the left side of the body (and vice versa).

Panel A. The stroke left a large hole in the part of the brain supplied by the middle cerebral artery, shown by the red arrows. The blue areas of the brain show what parts of the normal left side of the brain cortex and right cerebellum were activated when the patient was asked to open and close the fingers of his normal right hand. Arrow number 1 points to an area of the left hemisphere called the supplementary motor area; arrow number 2 points to the motor cortex of the left hemisphere, arrow 3 points to the right cerebellum (which controls coordination).

Panel B. When he was asked to open and close the fingers of his previously paralyzed left hand, the red areas of the brain show activation in many areas on both sides of the brain, including the motor area on the left side of the brain (arrow 1), the sensory and motor cortex on both sides of the brain (arrow 2), and the

supplementary motor cortex on the left side of the brain, and both sides of the cerebellum (arrow 3). This means that his brain had "rewired" itself using many different areas on both sides of the brain.

\section{WHAT DOES THIS PATIENT'S LATE RECOVERY MEAN?}

In the past it was believed that because recovery after a stroke was all over and done by 6 months to a year, there was no point in trying to persist with treatment such as physiotherapy to try to get more improvement. This patient's recovery, that began 23 years after a severe stroke and kept improving over another 14 years, gives hope to stroke patients and perhaps to patients with other kinds of brain injury. The hope is not only for improvement with intensive physiotherapy but also for new approaches to brain recovery that are being tested.

There is always more to learn, and more research to be done. That is what makes research fun. 


\section{ORIGINAL SOURCE ARTICLE}

Sörös, P., Teasell, R., Hanley, D. F., and Spence, J. D. 2017. Motor recovery beginning 23 years after ischemic stroke. J. Neurophysiol. 118(2):778-81. doi:10.1152/ jn.00868.2016

\section{REFERENCES}

1. Sörös, P., Teasell, R., Hanley, D. F., and Spence, J. D. 2017. Motor recovery beginning 23 years after ischemic stroke. J. Neurophysiol. 118(2):778-81. doi:10.1152/jn.00868.2016

2. Jones, T. A., and Adkins, D. L. 2015. Motor system reorganization after stroke: stimulating and training toward perfection. Physiology (Bethesda) 30(5):358-70. doi:10.1152/physiol.00014.2015

3. Chopp, M., and Zhang, Z. G. 2015. Emerging potential of exosomes and noncoding microRNAs for the treatment of neurological injury/diseases. Expert Opin. Emerg. Drugs 20(4):523-6. doi:10.1517/14728214.2015.1061993

4. Mayo, V., Sawatari, Y., Huang, C. Y., and Garcia-Godoy. F. 2014. Neural crestderived dental stem cells - where we are and where we are going. J. Dent. 42(9):1043-51. doi:10.1016/j.jdent.2014.04.007

5. Steinberg, G. K., Kondziolka, D., Wechsler, L. R., Lunsford, L. D., Coburn, M. L., Billigen, J. B., et al. 2016. Clinical outcomes of transplanted modified bone marrowderived mesenchymal stem cells in stroke: a phase 1/2a study. Stroke 47(7): 1817-24. doi:10.1161/STROKEAHA.116.012995

SUBMITTED: 27 December 2017; ACCEPTED: 07 August 2018; PUBLISHED ONLINE: 24 September 2018.

EDITED BY: Daniel W. Wesson, University of Florida, United States

CITATION: Spence JD (2018) Big Surprise: The Brain Can Recover Many Years After A Stroke. Front. Young Minds 6:41. doi:10.3389/frym.2018.00041

CONFLICT OF INTEREST STATEMENT: The author declares that the research was conducted in the absence of any commercial or financial relationships that could be construed as a potential conflict of interest.

COPYRIGHT () 2018 Spence. This is an open-access article distributed under the terms of the Creative Commons Attribution License (CC BY). The use, distribution or reproduction in other forums is permitted, provided the original author(s) and the copyright owner(s) are credited and that the original publication in this journal is cited, in accordance with accepted academic practice. No use, distribution or reproduction is permitted which does not comply with these terms. 


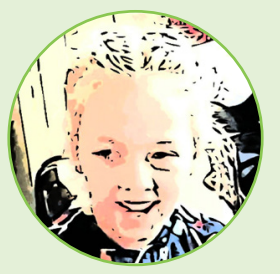

\section{REVIEWED BY}

\section{CLARA, AGE: 11}

I play piano, basketball, and lacrosse. I like going outside.

\section{AUTHOR}

\section{J. DAVID SPENCE}

I grew up in a Canadian oil camp in Talara, Peru, and was sent to boarding school in Canada from age 12. When my Dad was transferred to Miami while I was in university, I stayed in Canada because of the Vietnam War. I went to medical school in Canada and trained as a specialist in stroke prevention, and then did research training in San Francisco. I play golf (badly), love scuba diving, and sing in a very good choir: https://www.amabile.ca/primus-amabile-mens-choirplaces-1st-in-mens-category-of-national-competition/. My wife is family doctor; we have three sons and nine grandchildren. ${ }^{\star} d s p e n c e @ r o b a r t s . c a$ 